nais. A implantologia tem como opção para estes casos a realização de implantes de carga imediata os quais permite a colocação de uma coroa provisória e substituir a peça em falta. As facetas cerâmicas são uma técnica de reconstrução indireta utilizada para restaurar dentes com destruição parcial da coroa, alteração da forma, cor, tamanho e mal posições moderadas permitindo realizar tratamentos com altos requerimentos estéticos. Descrição do caso clínico: Paciente do género feminino, 18 anos, sem antecedentes de saúde relevantes, dirigiu-se à consulta na especialidade de implantologia por fratura radicular do 21 e coronal do 11, já reconstruído em compósito. Após a avaliação clínica, radiológica e protética foi sugerido a realização de exodontia do dente 21 , colocação de um implante com carga imediata, faceta cerâmica no 11 e gengivectomia do 11 e 12 para alinhamento da margem gengival permitindo ter um sorriso mais harmonioso. Discussão e conclusões: A utilização de implantes de carga imediata são uma opção para restaurar casos clínicos com implicações psicológicas e altos requerimentos estéticos após traumatismos em dentes anteriores. A utilização de facetas em dentes adjacentes a coroas sobre implantes permite homogeneizar posição, cor e forma quando o caso tem requerimentos estéticos. A utilização de materiais cerâmicos em restaurações de facetas e coroas, permite dar resistência, estabilidade da cor e resultados naturalmente estéticos aos dentes que precisam ser reabilitados com este tipo de tratamentos. Assim sendo uma ótima opção para o restabelecimento da função e estética no sector anterior.

http://doi.org/10.24873/j.rpemd.2019.12.488

\section{\#025 Deslocamento de implantes para o seio maxilar: A propósito de um caso clínico}

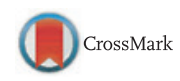

Cristiana Pereira*, Marisa Zenha, Abel Salgado, Raquel Carvalho, Carla Vasco

Faculdade de Medicina Dentária da Universidade do Porto, Instituto Superior de Ciências da Saúde do Norte, Faculdade Ciências da Saúde da Universidade Fernando Pessoa

Introdução: A reabilitação com implantes dentários tem sido considerada uma opção de tratamento previsível para os pacientes que apresentam edentulismo, parcial ou total, reabilitando a estética e a função mastigatória. Para o sucesso deste tratamento existem algumas premissas que devem ser tidas em conta para o sucesso da osteointegração. Para isso precisamos de saber qual a relevância de um bom diagnostico para estabelecer um plano de tratamento, que seja adequado, de forma individual, a cada caso. No entanto quando efetivamente temos o deslocamento do implante é importante saber quais serão as principais consequências da presença de um corpo estranho no seio maxilar. Descrição do caso clínico: Homem, 55 anos, caucasiano. Profissão: Mecânico. Sem antecedentes clínicos relevantes. Antecedentes cirúrgicos: Exodontia das seguintes peças dentárias: 2.4, 2.5 e 2.6 por motivo de cárie aproximadamente há dois anos, com posterior colocação de implantes sem enxerto ósseo nas respetivas locas. Numa das consultas de controlo verificou-se que o implante respetivo à localização do 2.6 estaria ausente. Dada a situação clinica o paciente decidiu dirigir-se a uma outra clinica medico- -dentária, e apresentou-se à consulta referindo ' exsudado purulento e odor fétido na cavidade oral', com evolução inferior a seis meses, assintomático, e com ausência de hemorragia. Ao exame radiográfico por CBCT (Cone Beam Computer Tomography), num corte paraxial verifica-se o deslocamento do implante para o seio maxilar. O tratamento consiste na remoção do implante através da técnica Caldwell-Luc. Foram fornecidas informações sobre os cuidados pós-operatorios ao paciente, sendo que todo o processo de cicatrização quer dos tecidos duros quer dos tecidos moles decorreu favoravelmente. Discussão e conclusões: A reabilitação do maxilar superior na sua zona posterior, cuja anatomia num mesmo indivíduo se vai modificando, por exemplo, com a idade, reveste-se de uma grande especificidade e dificuldade devido às particularidades desta zona, como a reabsorção da maxila posterior por parte da crista alveolar devido a perda dentária e à pneumatização do seio, o que provoca a diminuição da sua altura. Por estas razões, a implantologia da maxila posterior de um indivíduo edêntulo constitui um desafio para medicina dentária, sendo necessário que o clínico tenha formação e treino específico para a realizar.

http://doi.org/10.24873/j.rpemd.2019.12.489

\#026 Tratamento ortodôntico de assimetria facial
esquelética: A propósito de um caso clínico

António Bettencourt Lucas*, Adriana Armas Sobral, Patrícia Quaresma, Mariana Latas Rodrigues, Paula Bebiano, Sónia Alves

Instituto de Ortodontia da Faculdade de Medicina da Universidade de Coimbra

Introdução: A assimetria facial representa um desequilíbrio das estruturas esqueléticas homólogas da face e deve ser resolvida com um tratamento ortodôntico-cirúrgico combinado. Este tratamento deve visar não só a obtenção de uma oclusão ideal e um sistema estomatognático saudável, mas ainda a melhoria estética da face e o estabelecimento de uma função correta, com estabilidade a longo prazo. Assim, o objectivo deste trabalho é apresentar um caso clínico de assimetria facial e o tratamento ortodôntico-cirúrgico combinado. Descrição do caso clínico: Paciente do sexo feminino, com 16 anos e queixas a nível estético por apresentar assimetria facial e desvio do mento. O exame extraoral revelou assimetria facial com desvio do mento para a esquerda, perfil reto e sorriso com cunha posterior. O exame intraoral revelou gengivite, atrésia do maxilar superior, mordida cruzada à esquerda e Classe III de Angle molar e canina à direita e Classe II molar e Classe I canina à esquerda. O tratamento consistiu em quatro fases: pré-cirúrgica (Hyrax e aparelhos fixos bimaxilares), cirurgia ortognática bimaxilar, pós-cirúrgica (finalização ortodôntica) e de contenção (Placa de Hawley superior e contenção fixa inferior). Discussão e conclusões: É essencial ter uma equipa multidisciplinar no planeamento e tratamento de casos ortodontico-cirúrgicos, de modo a conduzir aos melhores resultados funcionais e estéticos. A coordenação entre o ortodontista e o cirurgião maxilo-facial é essencial.

http://doi.org/10.24873/j.rpemd.2019.12.490 